\title{
Biomechanical analysis of the cancellous screws implantation schemes in surgical treatment of flexible flatfoot in children
}

\author{
Gennadiy Koshman ${ }^{1}$, Vladimir Barsukov², Viktor Anosov ${ }^{3}$, Jolanta Pauk ${ }^{4}$ \\ ${ }^{1,3}$ Grodno State Medical University, Belarus \\ ${ }^{2}$ Yanka Kupala State University of Grodno, Belarus \\ ${ }^{4}$ Bialystok University of Technology, Poland \\ E-mails: ${ }^{1}$ genkoshman@gmail.com, ${ }^{2}$ v.g.barsukov@grsu.by, ${ }^{3}$ aviktor8@gmail.com (corresponding \\ author), ${ }^{4}$ j.pauk@pb.edu.pl \\ (Received 30 March 2016; accepted 22 April 2016)
}

\begin{abstract}
Carry out comparative biomechanical analysis of influence of the implantation scheme and characteristic sizes of cancellous screws on parameters of its strained condition, and elaborate guidelines for optimization of implantation parameters and decision for a material metalware choice. Performed mathematical modelling and comparative numerical analysis of the parameters of strained condition, slant and cantilevered schemes of implantation of cancellous screws, applied to a wide range of support loads variations acting on a screw. Made analysis of influence of size parameters (length of the overhanging part, angle with normal at supporting surface, core diameter) on the magnitude of the calculated stress that appear in compressed and extended zones of slant implanted screw. Carried out investigations reveal that short screws, installed on the hard circuit, from the standpoint of operational reliability according to the criteria of strength under static loading (occasional overload) and multicyclic loading have the highest capacity for work. Least favourable in application are slant and cantilevered implanted screws. With increasing length of cantilevered part and angle between axis of a screw and line of loading force calculated values of stress also increases. Screws of heat-treated stainless steel are preferred from the standpoint of saving bearing capacity with unit congestion due to increased plasticity in 4-5 times (residual strain at failure) compared with titanium alloys.
\end{abstract}

Keywords: cancellous screw, biomechanical analysis, strain, strength, flatfoot.

\section{Introduction}

Flatfoot is one of the most common reason orthopaedic consultation of children [1]. So far, the problem of conservative and surgical treatment of flexible flatfoot is not completely solved [2]. It offers a variety of methods of surgical correction, but none of them is not a panacea. Among commonly used in paediatric orthopaedics are methods based on blocking excessive pronation of the subtalar joint by setting foot in the tarsal sinus metal, plastic and biodegradable implants [3]. However, there is limitation of physiological motion of the subtalar joint and often develop postoperative complications in the form of avascular necrosis of the talus, fracture of the talus and calcaneus, tarsal sinus syndrome, the formation of cysts and migration of the implant [4]. The technically simplest in execution, more physiological and less dangerous from the standpoint of post-operative complications is biomechanical scheme based on the cancellous screws implanted in the lateral process of the talus body [5]. However, many questions related to the implantation and operation of the screws have not been studied. There are no clear scientific recommendations on the choice of material of screws (stainless steel or titanium alloy) and dimensional parameters of implant (length of the working part, the angle of cancellous screws to the supporting surface of the bone). 


\section{Methods}

Surgical correction of deformation is generally carried out simultaneously on both feet. The intervention is made through approach of up to $1 \mathrm{~cm}$ for skin fold above the level of the tarsal sinus $1 \mathrm{~cm}$ anteriorly and downward from the outer ankle. Further by the awl (4 mm diameter) formed the channel in the distal part of anterior surface of the lateral process of the talus. The channel is formed in an oblique direction from bottom to top, front and back, outside-in at an angle of $40 \pm 5^{\circ}$ in the coronal plane and $30 \pm 5^{\circ}$ in the sagittal. The direction of the channel should be such that the screw head lay on the upper part of the anterior process of the calcaneus, thereby creating a restriction of excessive pronation of the subtalar joint. The foot during implantation of cancellous screw held in supination, then we estimated volume of supination-pronation movements in the subtalar joint. The degree of correction is determined by the value of immersion of the screw - if the working part of the screw is long, the longitudinal arch of the foot is more high. Final assessment of the screw position makes by X-ray examination [5].

A general view of the most commonly used screws is shown in Figure 1, the characteristic size - in Table 1, the mechanical properties in Table 2.

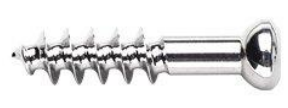

a

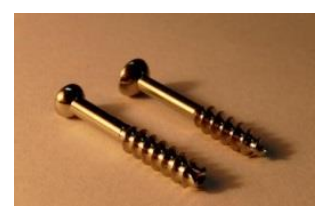

$\mathrm{b}$

Fig. 1. Steel (a) titanium and (b) a cancellous screws used to block excessive pronation of the subtalar joint

Table 1. The typical size of cancellous screws

\begin{tabular}{|c|c|c|c|c|}
\hline $\begin{array}{c}\text { Overall length } \\
\text { of the screw, } \\
\mathrm{mm}\end{array}$ & $\begin{array}{c}\text { Length of the } \\
\text { thread part, } \\
\mathrm{mm}\end{array}$ & $\begin{array}{c}\text { The diameter of the } \\
\text { rod in the threaded } \\
\text { part, } \mathrm{mm}\end{array}$ & $\begin{array}{c}\text { The diameter of the } \\
\text { rod in the non- } \\
\text { threaded part, } \mathrm{mm}\end{array}$ & $\begin{array}{c}\text { The diameter of } \\
\text { the thread, mm }\end{array}$ \\
\hline 25 & 12 & 2.3 & 4.0 & 4.0 \\
\hline 30 & 15 & 2.3 & 4.0 & 4.0 \\
\hline 35 & 17 & 2.3 & 4.0 & 4.0 \\
\hline 30 & 15 & 3.0 & 4.5 & 6.5 \\
\hline 35 & 17 & 3.0 & 4.5 & 6.5 \\
\hline
\end{tabular}

Table 2. The mechanical properties of the materials used for the manufacture of cancellous screws $[6,7]$

\begin{tabular}{|l|c|c|c|}
\hline \multicolumn{1}{|c|}{ The name and designation of the material } & $\begin{array}{c}\text { Strength limit, } \\
\mathrm{MPa}\end{array}$ & $\begin{array}{c}\text { Yield point, } \\
\mathrm{MPa}\end{array}$ & $\begin{array}{c}\text { Relative elongation } \\
\text { at break, \% }\end{array}$ \\
\hline $\begin{array}{l}\text { Corrosion-resistant steel (wrought stainless } \\
\text { steel) heat-treated ISO 5832-1-2010* }\end{array}$ & $490-690$ & 190 & 40 \\
\hline $\begin{array}{l}\text { Corrosion-resistant steel (wrought stainless } \\
\text { steel) cold-deformed ISO 5832-1-2010 }\end{array}$ & $860-1100$ & 690 & 12 \\
\hline Titanium alloy Ti6AL4V ISO 5832-3 & 860 & 780 & $8-10$ \\
\hline
\end{tabular}

Note: $*$ - the heat treatment method selects a manufacturer to achieve the desired properties

Theoretically there are three possible installation schemes cancellous screws: thrust (Fig. 2a), inclined (Fig. 2b) and console (Fig. 2c). 


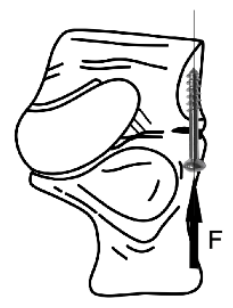

a

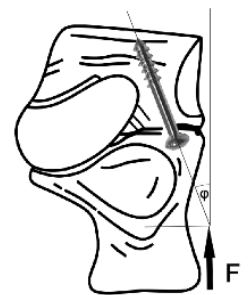

b

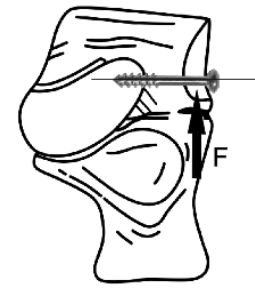

$\mathrm{c}$

Fig. 2. Installation schemes of cancellous screws: $\mathrm{a}$ - thrust; $\mathrm{b}$ - inclined; $\mathrm{c}$ - console

When installing in the thrust scheme force $F$ occurring in the reference area of contact with the bone screw directed along the screw axis, in console - perpendicular to the axis and inclined at $-\varphi$ at an angle there to.

As a basis for calculations take inclined installation scheme screws because of it in the form of special cases you can get a thrust $(\varphi=0)$, and a console $(\varphi=\pi / 2)$ schemes. This takes into account that the supporting force $F$ acts on the spherical bearing surface of the screw head (Fig. 3).

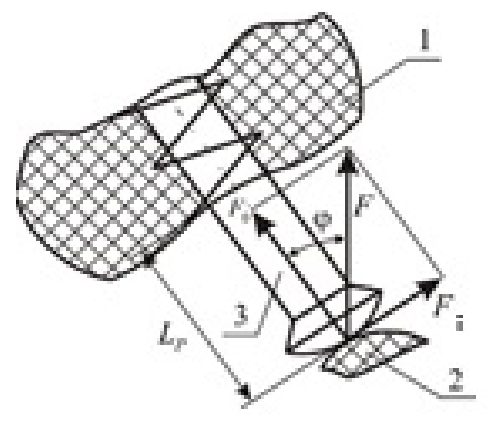

Fig. 3. Estimated biomechanical loading scheme obliquely set spongy screws: 1 - lateral process of the talus; 2 - calcaneus; 3 - cancellous screw

For ease of analysis we expand the force $F$ into two components-compressive axial directed along $F_{0}$ screw axis and perpendicular to the axis of the bending force $F_{i}$. In this axial force $F_{0}$ may be expressed by the reference $F_{i}$, and the angle $\varphi$ by using the following relationship

$F_{0}=F \cos \varphi$.

And bending force $F_{i}$ as:

$F_{i}=F \sin \varphi$.

Compression stress in the screw $\sigma_{c}$ :

$\sigma_{c}=\frac{4 F_{0}}{\pi d^{2}}=\frac{4 F \cos \varphi}{\pi d^{2}}$,

where $d$ - the diameter of the rod threaded part of the screw. 
Bending moment $M$ form force $F_{i}$ :

$M=F_{i} \cdot L_{p}=F \cdot L_{p} \sin \varphi$,

where $L_{p}$ - effective length of console part of the screw.

Bending stress $\sigma_{b}$ :

$\sigma_{b}=\frac{32 M}{\pi d^{3}}=\frac{32 F L_{p} \sin \varphi}{\pi d^{3}}$

Since the bending stresses are tensile in the same zone (the lower fiber) and compression in the other zone (upper fibers), then separately calculate the total tension in stretched and compressed parts as the sum or difference of bending stress and compression. The total compressive stress forces $\sigma_{c \Sigma}$ will be equal the sum of the stress of the longitudinal force $F_{0}$ and bending moment $M$ :

$\sigma_{c \Sigma}=\sigma_{i}+\sigma_{c}=\frac{4 F}{\pi d^{2}}\left(8 \frac{L_{p}}{d} \sin \varphi+\cos \varphi\right)$.

The maximum tensile stresses are the strain difference of the bending moment $M$ and longitudinal force $F_{0}$ :

$\sigma_{p \Sigma}=\sigma_{i}-\sigma_{c}=\frac{4 F}{\pi d^{2}}\left(8 \frac{L_{p}}{d} \sin \varphi-\cos \varphi\right)$

Formulae (5) - (6) are characteristic of the static loading of smooth rods. For estimating decrease strength properties of the screw when walking can act as a first approximation the stress concentration factor $K_{\sigma}$ which shows how many times the limit of a smooth rod of endurance more than the endurance limit of the rod with the concentrator (in this case with the thread). Thereby perform a comparative biomechanical analysis of the impact of dimensional parameters of implanted screws on the indicators of the state of stress is possible in the form of a relative.

\section{Results}

Thrust scheme. Taking into (2), (4) and (6) $\varphi=0$, receive $\sigma_{i}=0, \sigma_{c}=\sigma_{c \Sigma}$. The range of change of the reference force $F$ depends on the weight of a person, walking conditions and etc. Therefore, we will for the estimated settlement as a possible range $F=25-250 \mathrm{~N}$.

Table 3. Estimated value of the nominal compressive stresses in the rod screw at the persistent installation diagram

\begin{tabular}{|c|c|c|c|c|c|c|}
\hline \multirow{2}{*}{$\begin{array}{l}\text { Diameter of } \\
\text { the rod in } \\
\text { threaded part, } \\
\text { mm }\end{array}$} & \multicolumn{6}{|c|}{ The value of stress $\sigma_{c}(\mathrm{MPa})$ with force $F(\mathrm{~N})$} \\
\hline & 25 & 50 & 100 & 150 & 200 & 250 \\
\hline$\varnothing 2,3$ & 6,02 & 12,04 & 24,08 & 36,12 & 48,16 & 60,20 \\
\hline$\varnothing 3,0$ & 3,53 & 7,06 & 14,16 & 21,25 & 28,33 & 35,41 \\
\hline$\varnothing 4,0$ & 1,99 & 3,98 & 7,96 & 11,94 & 15,92 & 19,89 \\
\hline$\varnothing 4,5$ & 1,57 & 3,14 & 6,29 & 9,43 & 12,58 & 15,72 \\
\hline
\end{tabular}


From a comparison of the data with indicators of the strength of the used materials (Table 2) we can see that in considered range of loads in thrust scheme resulting stress loads is much less dangerous.

Console scheme. Taking into (2), (4) and (6) $\varphi=\pi / 2$, receive $\sigma_{c}=0$. Main result that in console scheme according cancellous screws to the calculated stress in the investigated range of sizes 4562 times larger than the thrust scheme and do not provide the necessary high load strength.

Inclined scheme. Obtained data shows that with increasing angle $\varphi$ from $0^{\circ}$ to $90^{\circ}$ values to compression and tensile stress increase many times, which is unfavourable from the standpoint of strength both in single overload and during multicyclic loading.

\section{Conclusions}

The complex of the research methods showed that from the standpoint of operational reliability according to the criteria of strength under static loading (occasional overload) and multicyclic loading highest workability characterized by short screws installed on the thrust scheme. The least favourable in the application are console and inclined set screws, and with an increase in the length of the arm portion and the angle between the line of action of the support efforts and screw axis of the calculated values of the stresses increase. Screws from heat-treated stainless steel are preferred from the standpoint of preserving the bearing capacity at single overload due to increased plasticity 4-5 times (residual strain at fracture) compared with titanium alloys.

\section{References}

[1] Jordan, K. P., et al. 2010. Annual consultation prevalence of regional musculoskeletal problems in primary care: an observational study, BMC Musculoskeletal Disorders 11(144): 1-10. http://dx.doi.org/10.1186/1471-2474-11-144

[2] Sviridenok, A. I.; Lashkovskij, V. V. 2009. Biomechanics and correction dysfunctions of feet. Grodno: GSMU. 279 p.

[3] Tamoev, S. K., et al. 2011. Subtalar arthroereisis in dysfunction posterior tibial tendon dysfunction, Vestnik Travmatologii i Ortopedii im. N. N. Priorova, 1: 54-58.

[4] Corpuz, M., et al. 2012. Fracture of the talus as a complication of subtalar arthroereisis, Journal of Foot and Ankle Surgery 51(1): 91-94. http://dx.doi.org/10.1053/j.jfas.2011.08.008

[5] Koshman, G. A., et al. 2011. Corrective lateral arthrorisis of subtalar joint in treatment flexible flatfoot in children. Grodno.

[6] GOST R ISO 5832-1-2010 Implants for surgery. Metallic materials. Part 1: Wrought stainless steel. Moscow, 2010. $12 \mathrm{p}$.

[7] GOST R ISO 5832-3-2014 Implants for surgery. Metallic materials. Part 3: Wrought titanium 6aluminium 4-vanadium alloy. Moscow, 2014. 2 p. 